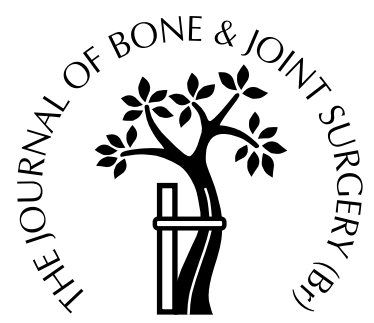

\title{
The fixation of the cemented femoral component
}

\author{
EFFECTS OF STEM STIFFNESS, CEMENT THICKNESS AND \\ ROUGHNESS OF THE CEMENT-BONE SURFACE
}

\author{
N. A. Ramaniraka, L. R. Rakotomanana, P.-F. Leyvraz \\ From the Orthopaedic Hospital, Lausanne, Switzerland
}

\begin{abstract}
$\mathbf{A}^{\mathrm{n}}$ fter cemented total hip arthroplasty (THA) there may be failure at either the cement-stem or the cement-bone interface. This results from the occurrence of abnormally high shear and compressive stresses within the cement and excessive relative micromovement.

We therefore evaluated micromovement and stress at the cement-bone and cement-stem interfaces for a titanium and a chromium-cobalt stem. The behaviour of both implants was similar and no substantial differences were found in the size and distribution of micromovement on either interface with respect to the stiffness of the stem.

Micromovement was minimal with a cement mantle 3 to $4 \mathrm{~mm}$ thick but then increased with greater thickness of the cement. Abnormally high micromovement occurred when the cement was thinner than $2 \mathrm{~mm}$ and the stem was made of titanium.

The relative decrease in surface roughness augmented slipping but decreased debonding at the cement-bone interface. Shear stress at this site did not vary significantly for the different coefficients of cement-bone friction while compressive and hoop stresses within the cement increased slightly.
\end{abstract}

J Bone Joint Surg [Br] 2000;82-B:297-303.

Received 2 November 1998; Accepted after revision 22 April 1999

After cemented total hip arthroplasty (THA) several types of movement may occur in the frontal plane in femoral components which have failed. ${ }^{1}$ These include metal pistoning within the cement and/or cement pistoning within

N. A. Ramaniraka, PhD, Research Engineer

Biomedical Engineering Laboratory, Swiss Federal Institute of Technology, CH-1005 Lausanne, Switzerland.

L. R. Rakotomanana, PhD, Senior Lecturer

P.-F. Leyvraz, MD, Professor of Orthopaedic and Trauma Surgery

Orthopaedic Hospital, Avenue Pierre-Decker 4, CH-1005 Lausanne,

Switzerland.

Correspondence should be sent to Dr L. R. Rakotomanana.

(C)2000 British Editorial Society of Bone and Joint Surgery

0301-620X/00/29613\$2.00

VOL. 82-B, No. 2, MARCH 2000 the femur, medial migration of the proximal part of the stem and lateral migration of the distal part, calcar pivot (with a mediolateral toggle of the distal end of the stem because of lack of cement), and bending cantilever fatigue due to medial migration of the proximal part of the stem and good fixation of the distal end in the cement. In addition, there may be torsional movement because of excessive axial torque. These movements may be associated with failure of the cement-stem interface as a result of debonding of the stem from the cement ${ }^{2,3}$ and of the cement-bone interface because of the breakdown of cement-bone interdigitation. ${ }^{4-6}$ These may result from the occurrence of abnormally high shear and compressive stresses within the cement and excessive debonding and slipping at both cement-stem and cement-bone interfaces. ${ }^{7-9}$ High compressive stress can cause fracture of the cement and subsequent subsidence of the stem ${ }^{10}$ while excessive slipping, resulting from pistoning and torsion of the stem, enhances the protrusion of cement debris. ${ }^{11}$ Slipping at the cement-bone interface may lead to necrosis of bone which has interdigitised with the cement, ${ }^{5}$ while debonding at the stem-cement interface may result in loosening $^{2}$ of the stem and periprosthetic osteolysis. ${ }^{12,13}$

Despite the importance of both types of the failure of the interface, most recent studies ${ }^{3,14-19}$ have focused either on a fully-bonded interface or on a fully-bonded cement-bone interface with a frictional cement-stem contact. One of the mechanical factors affecting the stress and micromovement at the interface is the coefficient of friction at both the cement-stem and cement-bone interfaces. Improving the bond at the cement-stem interface has been found to increase stress at the cement-bone interface. ${ }^{7,18,20}$ Analysis of the anchorage of the stem accounting for discontinuity at both cement-stem and cement-bone interfaces, seems to have been less well studied. The coupling effects of the roughness at the cement-stem and cement-bone interfaces have not been investigated.

Many factors have been implicated in the distribution of stress and micromovement. Experimental tests have shown the influence of the stiffness of the stem on cement stress $^{21,22}$ and numerical studies have indicated that stiffer stems induce higher distal stress ${ }^{23-25}$ and unload the proximal femoral bone, leading to stress shielding. ${ }^{22,26}$ Conversely, in vitro ${ }^{27}$ and in vivo, ${ }^{28}$ studies have concluded 
Table I. Applied forces of the femoral head and muscles

\begin{tabular}{lccc}
\hline & $\mathbf{F}_{\mathbf{x}}[\mathbf{N}]$ & $\mathbf{F}_{\mathbf{y}}[\mathbf{N}]$ & $\mathbf{F}_{\mathbf{z}}[\mathbf{N}]$ \\
\hline Femoral head & -320 & 448 & -1820 \\
Abductors & 430 & 0 & 1160 \\
Iliopsoas & 75 & 525 & 560 \\
\hline
\end{tabular}

that stems with lower stiffness are susceptible to wear, which may lead to the generation of particulate metallic debris. ${ }^{28-30}$ The influence of material stiffness on long-term behaviour remains unclear. Clinical ${ }^{31,32}$ and experimental ${ }^{33}$ studies have shown that the thickness of the cement has a strong influence on the stress magnitude. ${ }^{21}$ However, conclusions regarding the optimal range of thickness to ensure an excellent long-term result are contradictory. ${ }^{17,32-34}$ There have been no studies on the effects of the stiffness of the stem and the thickness of the cement on interfacial micromovement.

Our aim was to investigate the effects of the roughness between the bone and the cement, the stiffness of the stem and the thickness of the cement on the cement stress and on interfacial micromovement.

\section{Materials and Methods}

The three-dimensional geometry of the proximal femur was reconstructed using quantitative $\mathrm{CT}$. The distribution of the bone density corresponded to that measured immediately after implantation. Bone anisotropy was reproduced from anatomical observation and was implemented accordingly. ${ }^{35}$ The Young and shear moduli of each bone finite element were calculated according to the distribution of the bone density. ${ }^{36}$

A collarless, straight, symmetrical stem with a cement mantle of uniform thickness was digitised and inserted numerically in the reconstructed femur. The stem was implanted after the usual surgical procedure with normal reconstruction of the offset femoral head and positioned in neutral valgus. A previously developed three-dimensional finite-element model of the cemented bone-implant system was used. ${ }^{37}$

We considered two interfaces: the cement-stem and the cement-bone. As in previous models, the cement-stem interface was assumed to behave as a coulombian dry interface. ${ }^{18}$ In the present study, the cement-bone interface was also modelled to have discontinuous frictional contact, making it possible to calculate the debonding and slipping as well as the normal and shear stresses. The coefficient of friction at the cement-bone interface was set at $1.0,{ }^{6}$ which decreased to one-third when the cement roughness was removed. Young's modulus of the cement was 2200 $\mathrm{MPa}^{6}$

The loading conditions corresponded to single-limb stance in the gait cycle. The load bearing on the femoral head was simulated with a force of magnitude which was three times the body-weight (patient: 60 years; weight
$600 \mathrm{~N}$ ) and divided into axial, in-plane and out-plane directions $^{38}$ (Table I). The spatial reference system was defined as follows: the lateral-medial direction is denoted as $\mathrm{x}$, the anterior-posterior direction as $y$ and the vertical direction as z (up positive). ${ }^{39}$ The muscle forces of gluteus minimus, medius and maximus and iliopsoas were incorporated in the model. $^{40}$

Our study consisted of three parts. First, a titanium stem (Ti6Al4V) (Young's modulus $110000 \mathrm{MPa}$; Poisson's ratio 0.3 ) was considered and then compared with a cobaltchromium stem (Young's modulus $200000 \mathrm{MPa}$; Poisson's ratio 0.3 ). The thickness of the cement was set at $4 \mathrm{~mm}$ and the friction coefficients at the cement-bone and at the cement-stem interfaces at 1.0 and 0.4 , respectively.

Secondly, we investigated the sensitivity of the results with respect to thickness of the cement of 2, 3, 4, $5 \mathrm{~mm}$ and $7 \mathrm{~mm}$ for both types of implant. The coefficient of friction at the cement-bone interface was 1.0 and at the cementstem 0.4. For areas where the width of the bone did not allow the prescribed thickness of cement, the local distance between the outer surface of the implant and the cortical endosteal femur was used instead.

Thirdly, we studied the effects of the surface roughness of the cement-bone interface. The friction coefficient at the cement-bone interface was set successively at $0.4,0.6,0.8$ and 1.0 and the thickness of the cement mantle at $4 \mathrm{~mm}$.

\section{Results}

\section{Titanium alloy $v$ cobalt-chromium alloy}

Titanium implant. We measured the distribution of micromovement (debonding and slipping) at the cement-bone interface during a single limb-stance phase. Slipping was higher than $30 \mu \mathrm{m}$ at the proximal lateral, intermediate medial and distal lateral regions. The peak value was approximately $67 \mu \mathrm{m}$. The debonding was, in general, less than $10 \mu \mathrm{m}$ over almost the entire region of the interface. Nevertheless, the magnitude could exceed $30 \mu \mathrm{m}$ in the proximal medial and distal lateral regions (peak $35 \mu \mathrm{m}$ ). At the cement-stem interface, slipping exceeded $30 \mu \mathrm{m}$ over most of the proximal region and then decreased gradually towards the distal part.

At the cement-bone interface shear stress exceeded $1 \mathrm{MPa}$ at the proximal lateral, intermediate medial and distal medial regions (peak 2.4 MPa). Elsewhere, it was lower than 0.5 MPa. High compressive stress (peak 4.4 MPa) occurred in the same locations as high shear stress (peak 4.4 MPa). At the cement-stem interface, the peak shear stress was 3.0 MPa and the peak compressive stress was approximately $7.0 \mathrm{MPa}$.

Cobalt-chromium implant. At the cement-bone interface slipping was high at the proximal lateral, intermediate medial and distal lateral regions (peak values $68 \mu \mathrm{m}$ ). Debonding was less than $30 \mu \mathrm{m}$ over the entire interface (peak value $28 \mu \mathrm{m}$ ). Peak values for micromovement and stress at the cement-stem interface are shown in Table II 
Table II. Stress and micromovement at the cement-stem interface for both materials

\begin{tabular}{lcc}
\hline Thickness $(\mathbf{4} \mathbf{~ m m})$ & Titanium alloy & Cobalt-chromium alloy \\
\hline Debonding $(\mu \mathrm{m})$ & 73.6 & 63.1 \\
Slipping $(\mu \mathrm{m})$ & 116.9 & 109.0 \\
Pressure $(\mathrm{MPa})$ & 7.1 & 6.58 \\
Friction $(\mathrm{MPa})$ & 2.8 & 2.63 \\
\hline
\end{tabular}

(peaks: debonding $63 \mu \mathrm{m}$; slipping $109 \mu \mathrm{m}$; compressive stress 6.6 MPa; and shear stress 2.6 MPa).

Peak values of shear and compressive stress were higher than $1 \mathrm{MPa}$ and had nearly the same distribution as for the titanium stem (peak: compressive 4.2 MPa and shear 2.5 $\mathrm{MPa})$.

Effects of cement thickness. For both implants debonding at the cement-bone interface increased significantly with a thickness of cement of $2 \mathrm{~mm}$ (cobalt-chromium $115 \mu \mathrm{m}$ and titanium $93 \mu \mathrm{m}$ ) (Fig. 1). With a thickness greater than $3 \mathrm{~mm}$ debonding was less than $30 \mu \mathrm{m}$ over almost the entire interface. At the cement-stem interface, maximal debonding decreased slightly with the thickness of the cement. Minimal debonding for a titanium implant $(33 \mu \mathrm{m})$ occurred when the thickness of the cement was approximately $3 \mathrm{~mm}$ (Fig. 1) and for a cobalt-chromium stem $(28 \mu \mathrm{m})$ when the thickness of the cement was $4 \mathrm{~mm}$ (Fig. 1). In general the cobalt-chromium implant had a lower level of debonding than the titanium implant.

The evolution of slipping at the cement-bone and cement-stem interfaces related to the thickness of cement is shown in Figure 2. The behaviour of the titanium and cobalt-chromium implants was similar. For a thickness of cement of less than $3 \mathrm{~mm}$, slipping increased drastically and exceeded $100 \mu \mathrm{m}$ over the entire cement-bone interface (titanium $1650 \mu \mathrm{m}$ and cobalt-chromium $680 \mu \mathrm{m}$ ). The peak values for slipping were minimised when the cement thickness was $3 \mathrm{~mm}$ ( $52 \mu \mathrm{m}$ for both implants). For a thickness of cement in the range of 3 to $7 \mathrm{~mm}$ slipping remained constant, with highest values occurring in the
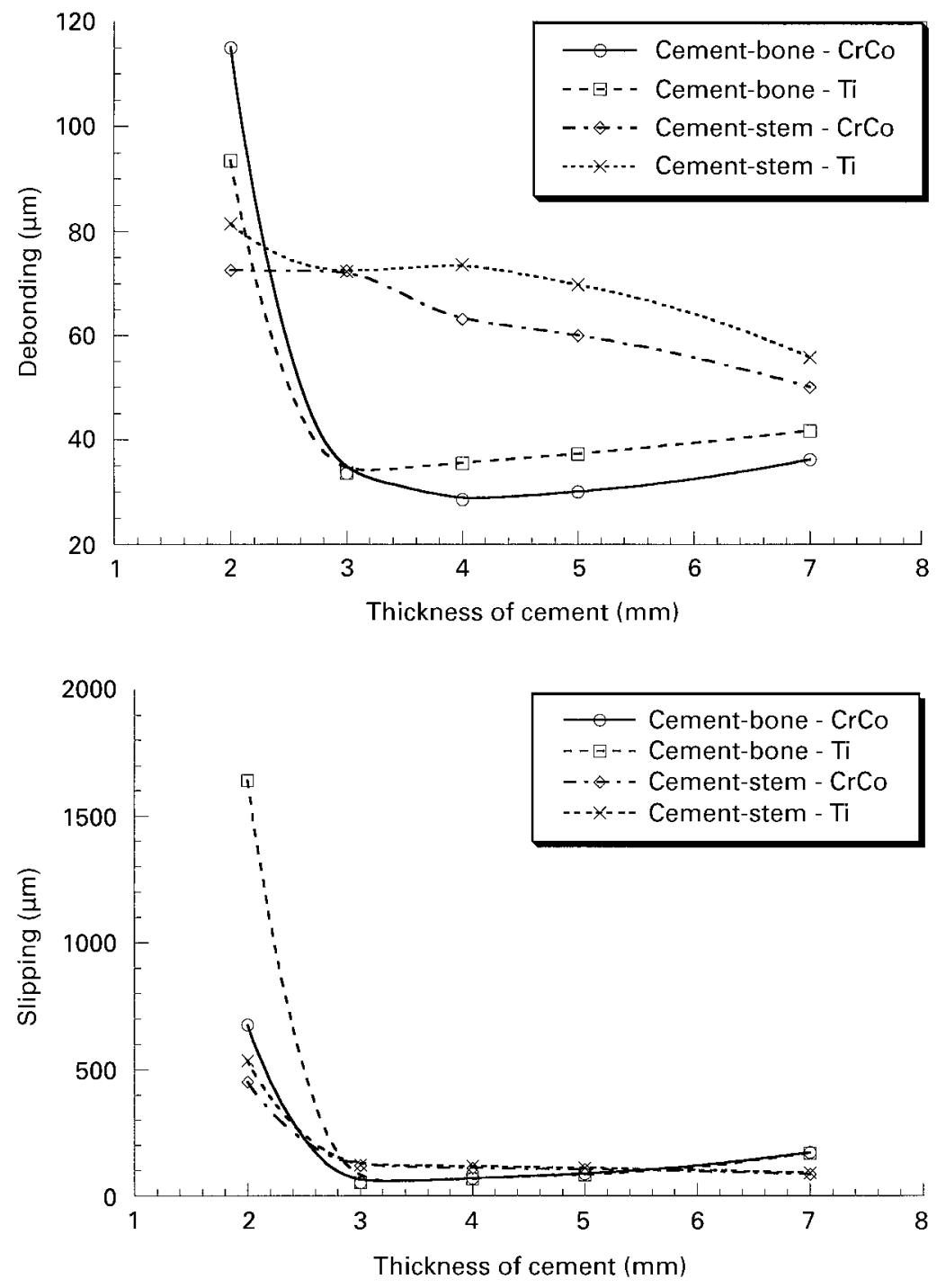

Fig. 1

Maximum values of microdebonding at the cementbone and cement-stem interfaces related to the thickness of the cement.
Fig. 2

Maximum values of microslipping at the cement-bone and cement-stem interfaces related to the thickness of the cement. 


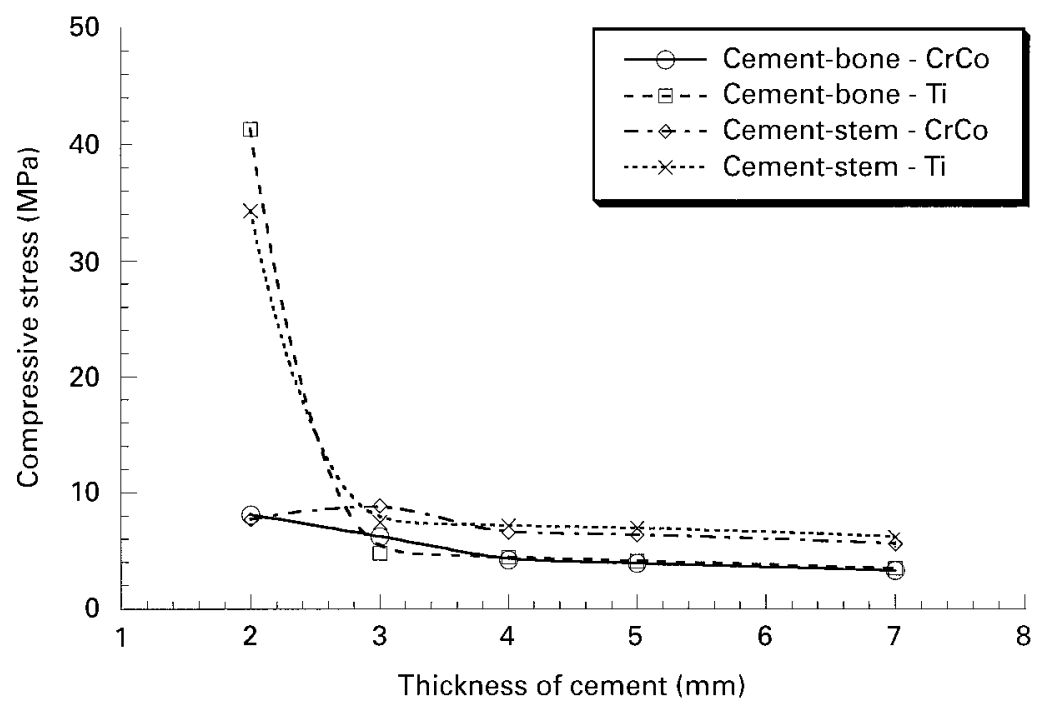

Fig. 3

Maximum values of compressive stress at the cementbone and cement-stem interfaces related to the thickness of the cement.

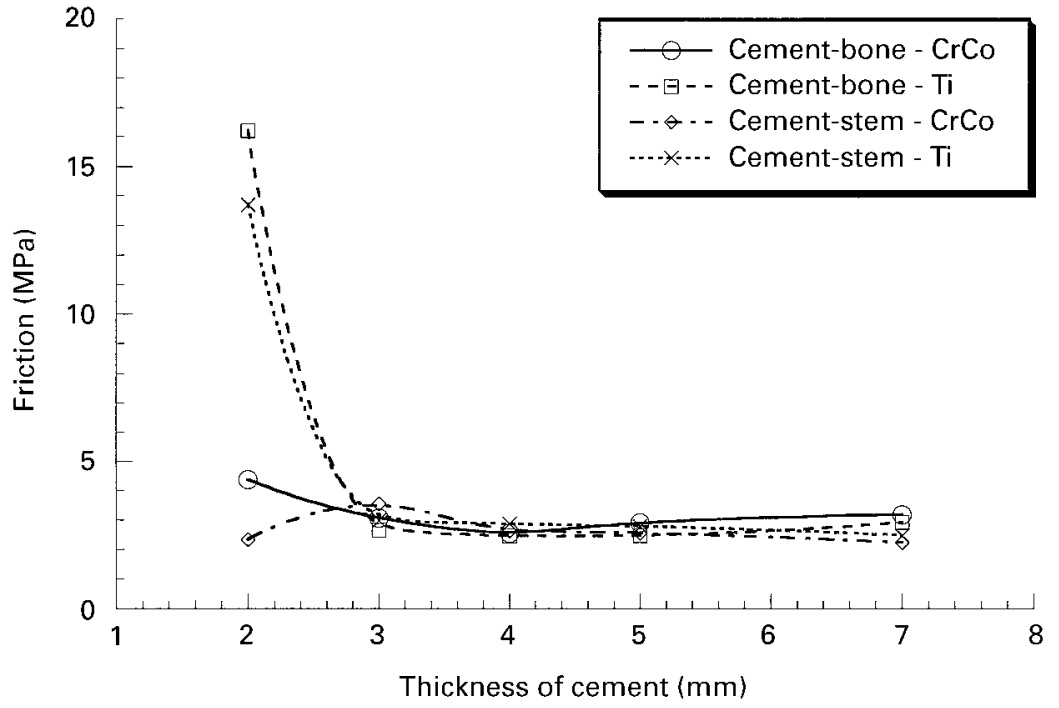

Fig. 4

Maximum values of frictional shear stress at the cement-bone and cement-stem interfaces related to the thickness of the cement.

proximal and distal lateral and medial regions of the cement-bone interface. For thicknesses greater than $7 \mathrm{~mm}$ the peak values of shear micromovement increased to $170 \mu \mathrm{m}$. In all cases slipping at the cement-bone interface was greater than slipping at the cement-stem interface.

The peak values of shear and compressive stress at both interfaces for thickness of cement greater than $3 \mathrm{~mm}$ were not significantly affected by the thickness of the cement for either implant (Figs 3 and 4). In addition, the region of high shear stress shifted gradually to the distal part of the implant with increase in thickness of the cement. For a thickness of $2 \mathrm{~mm}$, abnormally high compressive (Fig. 3) and shear stresses (Fig. 4) were observed at both interfaces for the titanium but there was only a slight increase for the cobalt-chromium stem. Overall, the shear stress was lower than the compressive stress.

Effects of friction coefficient. The magnitude of slipping at the cement-bone interface was higher than $30 \mu \mathrm{m}$ for the entire interface when a small coefficient of friction $(\mu=0.4)$ was used. The maximal values of slipping were higher for a low coefficient and remained nearly constant for higher levels. Conversely, the debonding was minimal for a lower coefficient and maximal for a higher. When the friction coefficient of the cement-bone interface was increased, slipping at the cement-stem interface increased and debonding decreased (Fig. 5).

The compressive stress was minimal for a low friction coefficient $(\mu=0.4)$ and increased gradually with increase in the coefficient, while the shear stress remained nearly constant (Fig. 6). Maximal compressive and shear stresses in the cement did not depend significantly on the friction coefficient at the cement-bone interface. Cement-bone stress (compressive and shear) was lower than cement-stem stress and the shear stress was lower than the compressive stress. 


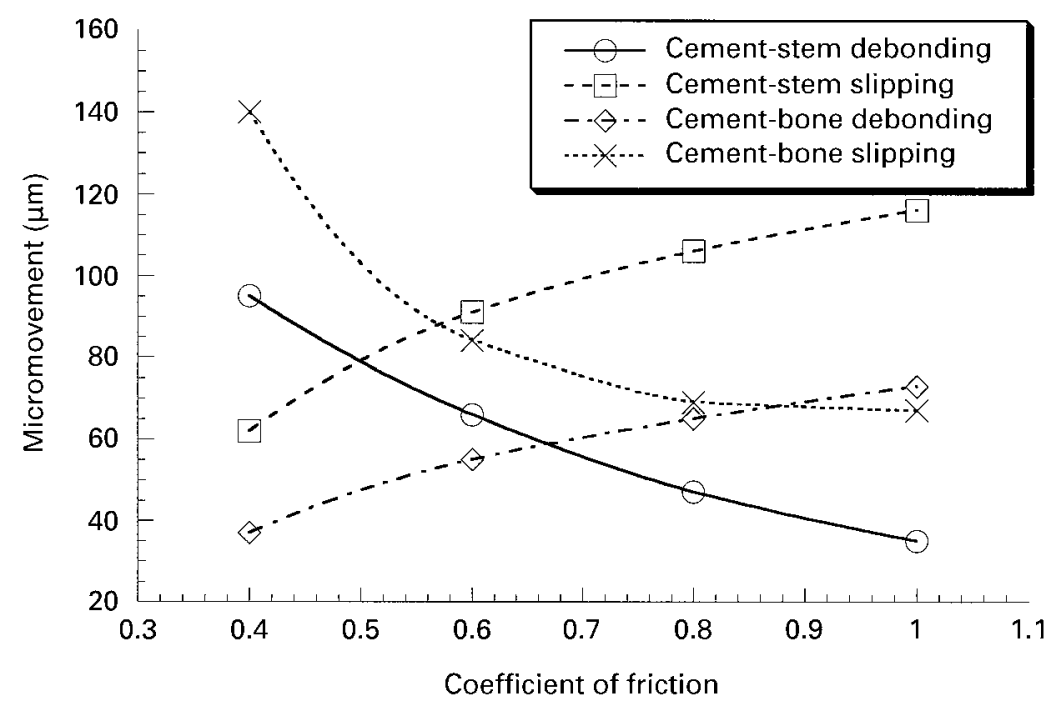

Fig. 5

Relative peak micromovement (microdebonding and microslipping) at the cement-bone and cement-stem interfaces related to the coefficient of friction at the cement-bone interface. The friction coefficient at the cement-stem interface was kept constant.

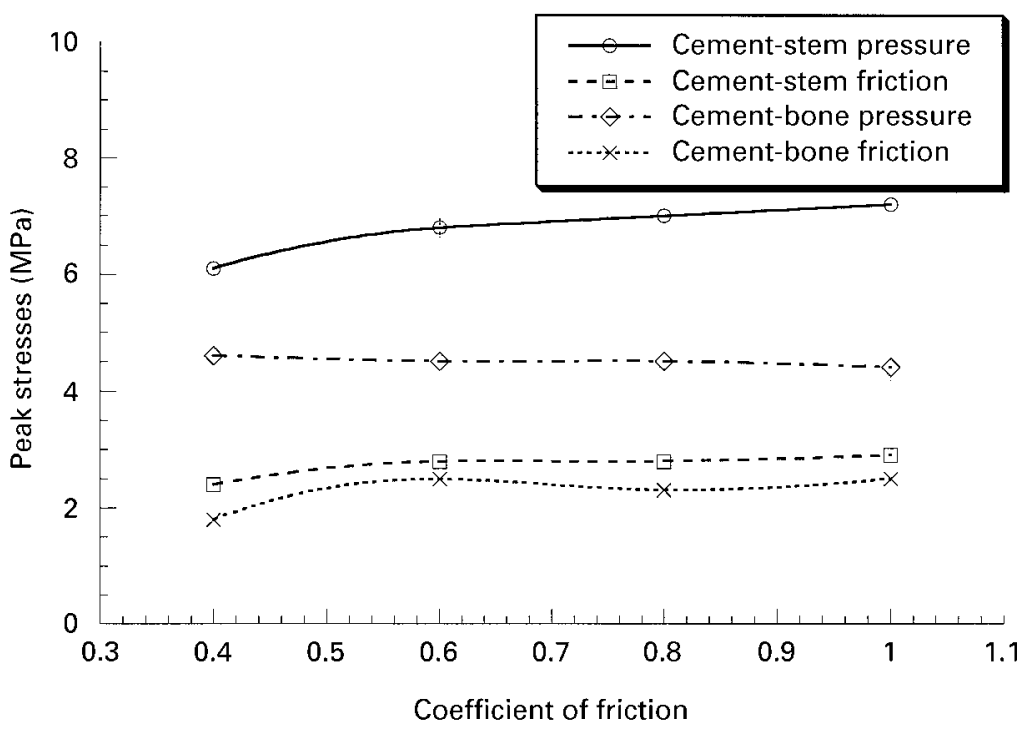

Fig. 6

Peak stress (compressive and shear) at the cement-bone and cement-stem interfaces related to the coefficient of friction at the cement-bone interface. The friction coefficient at the cement-stem interface was kept constant.

\section{Discussion}

Effects of stem stiffness. Cobalt-chromium and titanium alloys are widely used for the manufacture of femoral components. For a given shape a titanium stem is less stiff than a cobalt-chromium stem. The clinical issues for these two types of material remain controversial. Previous reports ${ }^{4,42}$ suggest that a stiffer stem reduces cement stress and enables it to last longer. Therefore cobalt-chromium seems to be the best material for THA. Previous numerical models ${ }^{43,44}$ have shown, however, that a cobalt-chromium stem unloads the proximal femur to a higher degree than a titanium stem and that this may enhance stress-shielding. $^{22,26}$ Theoretically, less stiff implants reduce stress within the stem and transfer load over a greater area of the cortical bone. $^{43,44}$

In our study, comparison of similar titanium and chro- mium-cobalt implants showed that the stiffness of the implant had no significant effect on micromovement at the cement-bone interface. Furthermore, the two stems presented comparable lower peak values for shear stress at this site. High stress occurred over almost the same area for the two implants. The occurrence of high slipping and high shear stress in the proximal part of the two stems may correspond to the clinical finding that osteolysis, due to debris particles generated by slipping, tends to occur laterally on the proximal part of the stem. ${ }^{45}$

Although the stiffness of the stem had no significant effect on micromovement and stress for a large range of cement thickness in the titanium stem, our study showed that a cement thickness of $2 \mathrm{~mm}$ drastically increased compressive and shear stress at both interfaces, which could lead to fracture of the cement. In turn, because of the combination of stress and micromovement, the tribo- 
physics of the two materials may be very different and may influence the biological reaction at the cement-stem interface.

Effects of cement thickness. The effect of the thickness of the cement on the initial stability has been investigated in previous studies, ${ }^{14,17,31-33}$ but the conclusions as to the optimal range of thickness are contradictory. Ebramzadeh et $\mathrm{al}^{33}$ showed that a cement mantle thicker than $5 \mathrm{~mm}$ was responsible for the radiolucent lines at the cement-bone interface and that one less than $2 \mathrm{~mm}$ thick induced fracture of the cement. By using numerical models based on fullybonded interfaces, Huiskes ${ }^{34}$ recommended a non-uniform thickness of cement ranging from 3 to $6 \mathrm{~mm}$ for the proximal part of the canal. Kwak et $\mathrm{al}^{17}$ recommended a uniform layer of 3 to $4 \mathrm{~mm}$. Crowninshield et al ${ }^{14}$ found that a decrease in the cross-sectional dimensions of the stem increased the stresses in both the stem and the cement. Brockhurst and Svensson ${ }^{31}$ suggested that the thickness of the cement mantle in the proximal medial region should be minimised. Fisher et $\mathrm{al}^{32}$ demonstrated that a thickness of 2 to $3 \mathrm{~mm}$ may provide a more favourable cement strain than a thinner mantle. These findings seemed to be explained by the occurrence of very high shear and compressive stresses ${ }^{3}$ which predicted a high risk of fracture of the cement for a cement mantle less than $3 \mathrm{~mm}$ thick. This is supported by experimental results ${ }^{33}$ which found that a thickness of less than $2 \mathrm{~mm}$ induced fracture of the cement.

Our study has shown that the thickness of the cement affected not only stress but also micromovement. A layer of cement of $2 \mathrm{~mm}$ thick increased shear stress proximally and at the tip of the stem, and increased micromovement over the entire cement-bone interface. These outcomes could be related to local bone necrosis and the occurrence of osteolysis in these regions due to the presence of the cemented debris resulting from interfacial shear friction. ${ }^{45}$ Surprisingly, thickness of cement greater than $7 \mathrm{~mm}$ increased slipping at the cement-bone interface, confirming other experimental results. ${ }^{33}$ Our study suggested that an optimum thickness of cement was in the range of 3 to $5 \mathrm{~mm}$.

In addition to the usual stress analysis the influence of the size and shape of the stem, its orientation and the nonuniformity of the thickness of the cement should be analysed.

Effects of friction coefficient. Mohler et $\mathrm{al}^{46}$ found that the failure of the bond at the cement-stem interface may initiate loosening. This remains controversial. The effects of the friction coefficient at the cement-stem interface on stress and micromovement have been studied in numerous models, ${ }^{15,19}$ but the effect of the roughness of the two interfaces has not yet been investigated.

Our results have shown that the decrease in the cementbone coefficient of friction increased slipping and decreased debonding at the cement-bone interface, the cement-stem coefficient of friction being maintained constant. Improvement of the bond at the cement-stem interface significantly increased the relative slipping at the cement-bone interface.
Such a phenomenon could be proposed as a biomechanical process promoting early failure at the cement-bone interface. ${ }^{7}$ The main change was the magnitude of the compressive stress which was probably due to the hoop effects resulting from the pistoning of the stem in the cement mantle. This abnormal increase in the compressive and hoop stresses induced an overloading of the cement mantle. This model could bring new insight to the biomechanical analysis of cemented stem fixation.

Our study had a number of limitations. We used only loading corresponding to a single limb-stance phase which did not constitute the worst case for the femoral component. The use of other types of loading, such as stair-climbing or standing from a chair, could possibly give more useful information.

No benefits in any form have been received or will be received from a commercial party related directly or indirectly to the subject of this article.

\section{References}

1. Gruen TA, McNeice GM, Amstutz HC. "Modes of failure" of cemented stem-type femoral components: a radiographic analysis of loosening. Clin Orthop 1979;141:17-27.

2. Harris WH. Is it advantageous to strengthen the cement-metal interface and use a collar for cemented femoral components of total hip replacements. Clin Orthop 1992;285:67-72.

3. Verdonschot N, Huiskes R. Cement debonding process of total hip arthroplasty stems. Clin Orthop 1997;336:297-307.

4. Bean DJ, Convery FR, Woo SL, Lieber RL. Regional variation in shear strength of the bone-polymethylmethacrylate interface. J Arthroplasty 1987;2:293-8.

5. Stone MH, Wilkinson R, Stother IG. Some factors affecting the strength of the cement-metal interface. J Bone Joint Surg [Br] 1989;71-B:217-21.

6. Walker PS. Human joints and their artificial replacements. Springfield: Charles C Thomas, 1977

7. Gardiner RC, Hozack WJ. Failure of the cement-bone interface: a consequence of strengthening the cement-prosthesis interface? J Bone Joint Surg [Br] 1994;76-B:49-52.

8. Jasty M, Maloney WJ, Bragdon CR, et al. The initiation of failure in cemented femoral components of hip arthroplasties. J Bone Joint Surg [Br] 1991;73-B:551-8.

9. Poss R, Brick GW, Wright RJ, Roberts DW, Sledge CB. The effects of modern cementing techniques on the longevity of total hip arthroplasty. Orthop Clin North Am 1988;19:591-8.

10. Phillips TW, Messieh SS, McDonald PD. Femoral stem fixation in hip replacement: a biomechanical comparison of cementless and cemented prostheses. J Bone Joint Surg [Br] 1990;72-B:431-4.

11. Rothman RH, Cohn JC. Cemented versus cementless total hip arthroplasty: a critical review. Clin Orthop 1990;254:153-69.

12. Burke DW, O'Connor DO, Zalenski EB, Jasty M, Harris WH. Micromotion of cemented and uncemented femoral components. $J$ Bone Joint Surg [Br] 1991;73-B:33-7.

13. Kärrholm J, Malchau H, Snorrason F, Herberts P. Micromotion of femoral stems in total hip arthroplasty: a randomized study of cemented, hydroxyapatite-coated and porous-coated stems with roentgen stereophotogrammetric analysis. $J$ Bone Joint Surg [Am] 1994;76-A:1692-705.

14. Crowninshield RD, Brand RA, Johnston RC, Milroy JC. The effect of femoral stem cross-sectional geometry on cement stresses in total hip reconstruction. Clin Orthop 1980;146:71-7.

15. Harrigan TP, Harris WH. A three-dimensional non-linear finite element study of the effect of cement-prosthesis debonding in cemented femoral total hip components. J Biomech 1991;24:1047-58.

16. Huiskes R. Some fundamental aspects of human joint replacement: analyses of stresses and heat conduction in bone-prosthesis structures.Acta Orthop Scand 1980:Suppl 185. 
17. Kwak BM, Lim OK, Kim YY, Rim K. An investigation of the effect of cement thickness on an implant by finite element stress analysis. Int Orthop 1979;2:315-9.

18. Mann KA, Bartel DL, Wright TM. The effect of using a plasmasprayed stem-cement interface on stresses in a cemented femoral hip component. Trans Orthop Res Soc 1992;17:317.

19. Verdonschot N, Huiskes R. Mechanical effects of stem cement interface characteristics in THR. Clin Orthop 1996;329:326-36.

20. Lu Z, Ebramzadeh E, McKellop H, Zahiri C, Sarmiento A. The influence of the stem-cement bonding strength on the cement stresses in total hip arthroplasty. Trans Orthop Res Soc 1992;17:377.

21. Crowninshield RD, Brand RA, Johnston RC, Pedersen DR. An analysis of collar function and the use of titanium in femoral prostheses. Clin Orthop 1981;158:270-7.

22. Crowninshield RD, Brand RA, Johnston RC, Milroy JC. An analysis of femoral component stem design in total hip arthroplasty. $J$ Bone Joint Surg [Am] 1980;62-A:68-78.

23. Andriacchi TP, Galante JO, Belytschko TB, Hampton S. Stress analysis of the femoral stem in total hip prostheses. J Bone Joint Surg [Am] 1976;58-A:618-24.

24. Bartel DL, Samehyeh E. The effect of cement modulus and thickness on stresses in bone-prosthesis systems. Trans Orthop Res Soc 1976;1:5-1.

25. Harrigan TP, Harris WH. Mechanical consequences of cement-metal interface disruption (debonding) at the distal tip of femoral total hip prosthesis. Trans Orthop Res Soc 1991;16:503.

26. McCarthy CK, Steinberg GG, Agren M, et al. Quantifying bone loss from the proximal femur after total hip arthroplasty. J Bone Joint Surg [Br] 1991;73-B:774-8.

27. Clarke IC, McKellop HA, McGuire P, Okuda R, Sarmiento A. Wear of Ti-6Al-4V implant alloy and ultrahigh molecular weight polyethylene combinations. In: Luckey HA, Kubli F Jr, eds. Titanium alloy in surgical implants, ASTM STP 796. Philadelphia: American Society for Testing and Materials, 1983:136-12.

28. Agins HJ, Alcock NW, Bansal M, et al. Metallic wear in failed titanium-alloy total hip replacements: a histological and quantitative analysis. J Bone Joint Surg [Am] 1988;70-A:347-56.

29. Black J, Sherk H, Bonino J, et al. Metallosis associated with a stable titanium-alloy femoral component in total hip replacement: a case report. J Bone Joint Surg [Am] 1990;72-A:126-30.

30. McKellop HA, Sarmiento A, Schwinn CP, Ebramzadeh E. In vivo wear of titanium-alloy hip prostheses. J Bone Joint Surg [Am] 1990;72-A:512-7.
31. Brockhurst PJ, Svensson NL. Design of total hip prosthesis: the femoral stem. Med Prog Technol 1977;5:73-102.

32. Fisher DA, Tsang AC, Paydar N, Milionis S, Turner CH. Effects of cement mantle thickness on cement strains in the femoral stem of total hip arthroplasty. Trans Orthop Res Soc 1995;711.

33. Ebramzadeh E, Sarmiento A, McKellop HA, Llinas A, Gogan W. The cement mantle in total hip arthroplasty: analysis of long-term radiographic results. J Bone Joint Surg [Am] 1994;76-A:77-87.

34. Huiskes R. The various stress patterns of press-fit, ingrown and cemented femoral stems. Clin Orthop 1990;261:27-38.

35. Rubin PJ, Rakotomanana RL, Leyvraz P-F, et al. Frictional interface micromotions and anisotropic stress distribution in a femoral total hip component. J Biomech 1993;26:725-39.

36. Carter DR, Hayes WC. The behaviour of bone as a two-phase porous structure. J Bone Joint Surg [Am] 1977;59-A:954-62.

37. Ramaniraka NA, Rakotomanana LR, Leyvraz P-F. Total hip arthroplasty: influence of cement thickness and bone-cement rugosity on the cement stress and on the femoral stem stability. Trans Euro Orthop Res Soc 1997;55.

38. Goldberg VM, Davy DT, Kotzar GL, et al. In vivo hip forces. In: Fitzgerald R, ed. Non-cemented total hip arthroplasty. New York: Raven Press, 1988; 251-6.

39. Terrier A, Rakotomanana LR, Ramaniraka NA, Leyvraz P-F. Adaptation models of anisotropic bone. CMBBE 1997;1:47-59.

40. Crowninshield RD, Brand RA. A physiologically based criterion of muscle force prediction in locomotion. J Biomech 1981;14:793-801.

41. Crowninshield RD, Pedersen DR, Brand RA, Johnston RC. Analytical support for acetabular component metal backing. In: The hip Proc of 11th Open Scientific Meeting of The Hip Society, St Louis, C. V. Mosby, 1983;207-9.

42. Friedman RJ, Black J, Galante JO, Jacobs JJ, Skinner HB. Current concepts in orthopaedic biomaterials and implant fixation. $J$ Bone Joint Surg [Am] 1993;75-A:1086-109.

43. Lewis JL, Askew MJ, Wixson RL, Kramer GM, Tarr RR. The influence of prosthetic stem stiffness and of a calcar collar on stresses in the proximal end of the femur with a cemented femoral component. J Bone Joint Surg [Am] 1984;66-A:280-6.

44. Tarr RR, Clarke IC, Gruen TA, Sarmiento A. Comparison of loading behaviour of femoral stems of Ti-6Al-4V and cobalt-chromium alloys: a three-dimensional finite element analysis. In: Luckey HA, Kubli F Jr, eds. Titanium alloys in surgical implants (ASTM STP 796). Philadelphia: American Society for Testing and Materials, 1982;88-14.

45. Willert HG, Bertram H, Buchhorn GH. Osteolysis in alloarthroplasty of the hip: the role of bone cement fragmentation. Clin Orthop 1990;258:108-21.

46. Mohler CG, Callaghan JJ, Collis DK, Johnston RC. Early loosening of the femoral component at the cement-prosthesis interface after total hip replacement. J Bone Joint Surg [Am] 1995;77-A:1315-22. 